\title{
Gender and Age-related Differences in Depressive Symptoms among Brazilian Children and Adolescents ${ }^{1}$
}

\author{
Makilim Nunes Baptista \\ Universidade São Francisco, \\ Campinas-SP, Brazil
}

\author{
Lisandra Borges \\ Universidade São Francisco, \\ Campinas-SP, Brazil
}

\author{
Alexandre Luiz de Oliveira Serpa \\ Hogrefe Cetepp, \\ São Paulo-SP, Brazil
}

\begin{abstract}
Assessing and discovering the major depression symptoms among men and women, even in the early stages of development, are key elements in the construction and standardization of psychometric instruments. This study aimed to evaluate the differences in the expression of depressive symptoms by gender and age group. The sample consisted of 1,697 students aged 8-17 years. The data collected through the Escala Baptista de Depressão infantojuvenil were submitted to item response theory analysis. Results showed that internalizing symptoms are more common in girls and externalizing symptoms in boys. It can be concluded that standards for boys and girls should differ, just like different standards are needed for children and adolescents.
\end{abstract}

Keywords: child depression, psychological assessment, adolescents

\section{Diferenças de Sexo e Idade Relacionadas aos Sintomas Depressivos entre Crianças e Adolescentes Brasileiros}

\begin{abstract}
Resumo: Avaliar e conhecer os principais sintomas depressivos entre homens e mulheres, inclusive nas fases de desenvolvimento iniciais, são elementos fundamentais no desenvolvimento e normatização de instrumentos psicométricos. $\mathrm{O}$ estudo teve como objetivo avaliar as diferenças na expressão de sintomas depressivos por sexo e faixa etária. A amostra foi composta por 1.697 alunos com idades entre 8-17 anos. Os dados coletados com a Escala Baptista de Depressão Infantojuvenil foram submetidos à análise de teoria de resposta ao item. Os resultados mostraram que os sintomas de internalização são mais comuns em meninas e sintomas de externalização em meninos. Pode-se concluir que as normas para meninos e meninas devem diferir, assim como são necessários padrões diferentes para crianças e adolescentes.
\end{abstract}

Palavras-chave: depressão infantil, avaliação psicológica, adolescentes

\section{Género y Diferencias Relacionadas con la Edad en los Síntomas Depresivos entre los Niños y Adolescentes Brasileños}

\begin{abstract}
Resumen: Evaluar y conocer los síntomas principales de la depresión mayor entre los hombres y las mujeres, incluso en las primeras etapas de desarrollo son elementos fundamentales en la construcción y la normalización de los instrumentos psicométricos. Este estudio tuvo como objetivo evaluar las diferencias en la expresión de los síntomas depresivos por sexo y grupo de edad. La muestra estuvo conformada por 1.697 estudiantes entre 8 y 17 años. Los datos recogidos a través de la Escala Baptista de Depressão Infanto-Juvenil se sometieron al análisis de la teoría de respuesta al ítem. Los resultados mostraron que los síntomas de internalización son más comunes en las niñas y los síntomas de externalización son más comunes en los niños. Se puede concluir que las normas para niños y niñas deben ser diferentes, al igual que se necesitan normas diferentes para niños y adolescentes.
\end{abstract}

Palabras clave: depresión infantil, evaluación psicológica, adolescentes

The empirical finding that children could be affected by mood disorder refuted the belief that this age group would lack the maturity to experience depressive symptoms (Luby, 2010). By now, childhood depression is a recognized clinical disorder, thus directing researchers towards other questions. What are the most common symptoms children and adolescents express? Do symptoms differ between boys and girls? Do symptomatic differences exist as a function of age?

On the one hand, diagnostic manuals only offer

\footnotetext{
${ }^{1}$ Support: Coordination for the Improvement of Higher Education Personnel (CAPES) - Process No. 0347.0.142.000-11

${ }^{2}$ Correspondence address:

Makilim Nunes Baptista. Rua Waldemar César da Silveira, 105. Vila Cura D’Ars (SWIFT). CEP 13045-510. Campinas-SP. Brazil. E-mail: makilim01@gmail.com
}

exceptions to diagnose depressive disorder and have no system of criteria and symptoms for each age group (American Psychiatric Association [APA], 2013). On the other hand, scientific studies have targeted screening for depressive symptoms in children. In this sense, researchers (Chrisman, Egger, Compton, Curry, \& Goldston, 2006; Gaffrey, Belden, \& Luby, 2011; Luby, Gaffrey, Tillman, Abril, $\&$ Belden, 2014) understand that symptoms vary according to age, highlighting the importance of the maturation processes of the developmental stages. It should also be kept in mind that cultural processes can influence the expression of symptoms between the sexes (Nolen-Hoeksema, 2002; Tsai $\&$ Chentsova-Dutton, 2002).

Therefore, some symptoms may occur more incisively in younger age groups, such as disinterest in play and 
schoolwork, irritability and hyperactivity, psychosomatic symptoms (headaches), enuresis, problems with sleep, crying and rage. In this stage suicidal ideation is verbalized as the desire to sleep forever, to leave, or to disappear (Baptista, 2011). As the child continues to develop, somatic symptoms are replaced by psychological ones (Lima, 2004).

Thus, in adolescence, complaints of pain are less frequent - taking their place: a decrease in school performance; increased intolerance for routine; social withdrawal; hopelessness; thoughts of guilt, irritability, rebellion; general disinterest; weariness and fatigue; preoccupation with body image; indecision and violent suicides. It is also common for the adolescent to feel bored and empty rather than depressed (Luby et al., 2014).

Another aspect to note is the difference in the presentation of depressive symptoms in relation to gender (Hamilton, Hamlat, Stange, Abramson, \& Alloy, 2014). There is no consensus in the literature in this regard. According to some authors (Chrisman et al., 2006; Eapen \& Crncec, 2012; Harkness et al., 2013; Thapar, Collishaw, Pine, \& Thapar, 2012), the contrast between boys and girls appears between the ages of 12 and 14 years, when the girls begin to show a greater number of depressive symptoms than boys. Other researchers, however, observed these differences somewhat later, between 15 and 18 years old (Essau, Lewinsohn, Seeley, \& Sasagawa, 2010).

Differences between the genders may be related to socialization, hormones and/or stressful events associated with adolescence (Luby et al., 2014). According to Baptista (2011) and Girgus and Yang (2015), they stem from social and educational practices of power and control, physical abuse, emotional management and coping strategies, ruminating negative thoughts, sexual orientation and negative body image.

Also according to the literature, boys exhibit more externalizing symptoms, while girls possess more internalizing symptoms (Fanti \& Henrich, 2010; Keegstra, Post, \& Goorhuis-Brouwer, 2010). The externalizing symptoms involve impulsivity, physical or verbal aggression, agitation and provocation. Internalizing may be observed as excessive worry, withdrawal, sadness, shyness, insecurity and fear (Benarous, Hassler, Falissard, Consoli, \& Cohen, 2015).

Sorensen, Nissen, Mors and Thomsen (2005) investigated possible differences in depressive symptoms linked to age and gender in a clinical sample of 199 children between 8-13 years of age. In relation to age, the older participants (12-13 years) showed differences in anhedonia, hypersomnia, loss of appetite and decreased ability to concentrate, while the younger participants (8-11 years) expressed more feelings of worthlessness. No significant differences were found according to gender.

Baji et al. (2009) evaluated 559 children and adolescents from 7 to 15 years of age diagnosed with depression. Two psychiatrists evaluated the results and verified the existence of different symptom patterns between age and gender groups. The authors explained that depressed mood and irritability were the most common symptoms among children and anhedonia was the least frequent. Regarding age, the symptoms altered significantly by year, with depressed mood, hypersomnia, motor retardation, fatigue, thoughts of death and suicidal ideation increased in intensity according to the child's development, while motor restlessness decreased. Girls were more prone to anhedonia, hypersomnia, insomnia and somatic complaints. The study suggests that, contrary to previous reports, a depressed mood is extremely common in this population and that the presentation of depression becomes more neurovegetative both with age and for females, including symptoms that reflect the body processes, such as sleep and motor functioning.

Studies on depression in children and adolescents suggest that, prior to puberty, there is a trend for boys to have more depressive symptoms than girls (Diamantopoulou, Verhulst, \& van der End, 2011; Johnson \& Whisman, 2013; Rohde, Lewinsohn, Klein, Seeley, \& Gau, 2014). Around the age of 13 to 14 years, girls begin to consistently present higher depression rates. Petersen, Sarigiani and Kennedy (1991), in a longitudinal study of children aged 11 to 17 years found sex differences in depressed mood before the age of 13 years, which were intensified at the age of 16 and 17 years, when the girls had higher scores than boys. In fact, there is a gap in the literature about evidence that could explain the differences in the principal symptoms among children and adolescents, and whether girls and boys divide into groups of specific symptoms, which could require different correction forms of assessment tools (Carle, Millsap, \& Cole, 2008).

Although there is some agreement about the symptomatic differences between children and adolescents, there is no consensus about which symptoms are typical for each age group. Therefore, the aim of this study was to assess whether or not differences in depressive symptoms are a function of gender and age group. An additional objective is to explore the characteristics of potential differences.

\section{Method}

\section{Participants}

The convenience sample consisted of 1,697 grade school students (between $5^{\text {th }}$ and $9^{\text {th }}$ grade) and high school (from $10^{\text {th }}$ through $12^{\text {th }}$ grade), in public schools in the states of Minas Gerais and São Paulo, Brazil. They are predominantly female $(53.4 \%, n=907)$, with an average age of 12.85 years $(S D=$ 2.44), ranging from 8 to 17 years of age. Participants were divided into two groups, the first called G1 $(n=708)$, with children aged 8 to 11 years, and the second G2 $(n=1235)$, with adolescents from 12 to 17 years of age. Group division was based on the limits established by the Statute of Children and Adolescents (Lei No. 8.069, 1990), which considers those under 12 years of age to be children, and those between 12 and 18 years incomplete to be adolescents.

\section{Instruments}

EBADEP-IJ - Escala Baptista de Depressão - Versão infantojuvenil (Baptista, 2011) aims to track symptoms of 
depression in children and adolescents aged 8 to 17 years. EBADEP-IJ was developed based on a set of descriptors coming from psychiatric manuals, such as DSM-IV-TR and ICD-10, as well as others deriving from Depression Cognitive Theory; Ferster's Principles of Operant Behaviour and the studies by Weinberg, Rutman, Sullivan, Pencik and Dietz. It consists of 52 items with three-point Likert type responses, with the options Rarely, Sometimes and Often. The bifactorial structure showed the best fit $(\mathrm{RMSR}=0.04, \mathrm{RMSEA}=0.049[0.048$ to 0.050$])$, with $32 \%$ of the variance explained. The minimum residual (minres) extraction method was used, with direct oblimin rotation, and the correlation between the two factors was 0.33 .

The item analysis of each factor showed that the factor separation was due to the directionality of each symptom. Thus, positive symptoms were referred to as Factor 1, with a total of 17 items. The reliability of Factor 1 was evaluated through internal consistency analysis, with a Cronbach's alpha of 0.93 and Guttman lambda of 0.93. Examples of item headers in this factor are "I'm happy with my life," "I sleep well" and "I believe in a good future." Negative symptoms were referred to as Factor 2, containing 28 items, and its internal consistency was assessed by Cronbach's alpha and Guttman's lambda, whose coefficients corresponded to 0.91 and 0.92 , respectively. Some examples of item headers in Factor 2 are "I feel irritated," "Living gets difficult for me" and "I feel like crying."

\section{Procedure}

Data collection. Upon approval by the cities' Education Departments, the survey was sent to the Research Ethics Committee at Universidade São Francisco in 2011. All parents/ guardians signed the Informed Consent Form. The survey was applied collectively in the classroom. After the instructions, the children were asked to mark with an " $X$ " one sentence for each item, according to his/her feelings and thoughts over the past two weeks prior to application. The time allotted for this assessment was 30 minutes. No inclusion or exclusion criteria were set at this moment because of the exploratory nature of the research. During the test construction, all issues about the children's understanding of items and instructions were solved.

Data analysis. To evaluate intergroup differences, we apply one method of the "differential item functioning" (DIF) class, usually linked to the item response theory. This class comprises a set of analysis strategies that intend to evaluate variations in the items' behaviour, taking into consideration different assumptions and aims. Each strategy should be used to answer a specific question. Below, we described the methodology and the DIF method used in this research.

Initially, the assumptions of the item response theory were tested to verify the suitability of the instrument items submitted for analysis. Then, the items' characteristics were studied, using two different polytomic models: Andrich's Gradual Scale Model (Andrich, 1978), and Samejima's Graded Response Model (Samejima, 1969). These models were chosen because their assumptions fit the expected growth of the individuals' symptom severity better, as addressed by the three alternative answers for each item. As no relevant differences were found between the parameters estimated by both models, it was decided to use the gradual scale model, as it is more parsimonious. Given the model chosen, the scores were produced and the items were then submitted to differential item functioning (DIF) analysis to look for item invariance across population subgroups. These were used as elements to generate the reference groups for gender and age. Subsequently, data were sectioned in relation to the age group they belonged to, the first group being the children (8-11 year-olds) and the second the adolescents (12-17 year-olds). The differential analysis was performed by means of Andersen's Likelihood Ratio Test (Andersen, 1973). This technique is based on the comparison of estimated difficulty parameters for different subgroups of a given sample, an appropriate test when there are violations of the assumptions of item monotonicity and sufficiency (Mair \& Hatzinger, 2007; Teresi \& Fleishman, 2007).

\section{Ethical Considerations}

The present study received approval from the Research Ethics Committee at Universidade São Francisco, protocol 0347.0.142.000-11. Therefore, in this study, the ethical aspects of research involving human beings were met: the parents' informed consent was obtained and the confidentiality in data treatment and analysis was assured.

\section{Results}

Initially, data from the total sample were separated only in function of sex and were submitted to DIF analysis. In this condition, no differences in the item functioning were found. Next, still for the total sample, data were split as a function of age - child and adolescent groups - when some items with differential functioning were found. Table 1 summarizes the principal differences found in relation to symptoms and indicates items that exhibited DIF for each age group in each of the scale factors.

Table 1

Descriptors of items according to age group

\begin{tabular}{ccc}
\hline Group & Positive Items & Negative Items \\
\hline Children & & Loneliness \\
& Helplessness \\
Adolescents & Hope & Suicide Ideation \\
& Optimistic Perspectives on the Present & Low Self-Esteem \\
& Higher Self-Esteem & \\
\hline
\end{tabular}


In Table 1, it can be noted that, for positive items (Factor 1), only three showed DIF, all of them in the adolescent group. Based on an evaluation of their descriptors, it can be affirmed that teenagers were more hopeful, with better perspectives on the present and higher self-esteem when compared to children. For the negative items (Factor 2), four showed differential behavior, this time equally divided between the age groups. The children presented more fear of separation and greater feelings of loneliness, while adolescents presented more suicide ideation and low self-esteem.

It is important to draw attention to the fact that some descriptors are represented by more than one item, be it positive or negative. For example, in Factor 1, the item that describes self-esteem is "I am smart." Thus, one can say that teenagers showed no doubts about their abilities. However, in Factor 2, another item that measures self-esteem was highlighted, "I feel that people do not want to be with me."

Next, in order to further investigate the possible differences in the expression of depressive symptoms, it was decided to stratify the two age groups as a function of the gender of their components. In this approach, differences between gender were presented, commonly mentioned in the literature. Table 2 displays the descriptors with differential functioning in relation to gender for the children's group.

Table 2

Descriptors of items for Children and Adolescents Regarding Gender

\begin{tabular}{lll}
\hline & Children \\
\hline & Factor 1 & Factor 2 \\
\hline \multirow{4}{*}{ Boys } & Problem Solving & Low Concentration \\
& & Increased Perception of Illness \\
& & Suicide Ideation \\
& & Lower Sociability \\
& & Loneliness \\
\hline
\end{tabular}

\begin{tabular}{|c|c|c|}
\hline Girls & $\begin{array}{l}\text { Pleasure in Activities } \\
\text { Appetite } \\
\text { Higher Self-Esteem } \\
\text { Hope } \\
\text { Elevated Mood } \\
\text { Greater Sociability }\end{array}$ & $\begin{array}{l}\text { Crying } \\
\text { Desire to Cry }\end{array}$ \\
\hline \multicolumn{3}{|c|}{ Adolescents } \\
\hline & Factor 1 & Factor 2 \\
\hline Boys & $\begin{array}{l}\text { Appetite } \\
\text { Higher Self-Esteem }\end{array}$ & $\begin{array}{l}\text { Aggressiveness } \\
\text { Lower Self-Esteem } \\
\text { Low Concentration } \\
\text { Hopelessness } \\
\text { Fatigue } \\
\text { Suicide Ideation } \\
\text { Indecision } \\
\text { Negativity } \\
\text { Lower Sociability } \\
\text { Loneliness }\end{array}$ \\
\hline
\end{tabular}

\begin{tabular}{lll} 
& Pleasure in Activities & \\
Girls & Higher Self-Esteem & Crying \\
& Hope & Depressed Mood \\
& $\begin{array}{l}\text { Scholastic Productivity } \\
\text { Sociability }\end{array}$ & Loneliness \\
& Desire to Cry \\
\hline
\end{tabular}

As can be seen in Table 2, the girls' group of children showed DIF for a greater number of positive and negative descriptors when compared to boys. For positive items, in relation to symptom descriptors, the results indicated that the girls do not seem to have symptoms related to change in appetite, they have higher self-esteem, greater socialization and enjoyment in performing activities. Moreover, they have more hope and are happier than boys. The negative items showed a larger number of items with differential functioning than the items in the positive category. In this factor, the girls reported a greater desire to cry and also indicated crying more than the boys. The boys, in turn, were more aggressive, sought social isolation and reported feeling more alone, as well as presenting concentration difficulties. In addition, they presented a greater magnitude of suicide ideation and felt sicker than others.

Applying the same stratification to the adolescent group, a large number of items with DIF were also found, just like in the children's age group. The girls showed a higher number of positive and negative descriptors when compared to boys. The analysis results are also shown in Table 2.

Regarding the adolescent group (12 to 17 years), the girls, besides presenting greater sociability, reported feeling more hopeful, useful and productive in school, and indicated feeling more pleasure in performing activities. In contrast, the boys seem to have higher self-esteem and normal appetite. For negative items, sadness, low/sad mood, desire to cry as well as crying itself were reported more frequently in the group of girls. Note that the desire and the act of crying remained constant among girls regardless of age, thereby appearing to be an important marker for the characterization of depression in girls. For boys, symptoms of isolation, loneliness, difficulty concentrating, aggressiveness and suicide ideation persist in adolescence. In addition, they presented negativity, indecisiveness, hopelessness, fatigue and low self-esteem. In Table 2, it is important to draw attention to the fact that the descriptors that measure self-esteem are, in Factor 1, "I like myself as I am." In Factor 2, another item that measures self-esteem was highlighted, "I feel that people do not want to be with me."

\section{Discussion}

Understanding the differences of expression and the development of depressive symptoms for individual characteristics entails important implications for knowledge about the course of the disease and, consequently, the creation and development of effective interventional approaches for each age, as well as the possibility of gender- and age-specific standards in depression screening instruments. According to this premise, in the present study, we investigated the differences in the expression of depressive symptoms based on sex and age group of Brazilian children and adolescents. In addition, as Nolen-Hoeksema (2002) and Tsai and ChentsovaDutton (2002) stated, it can be critical to better understand how culture can shape the expression of symptoms. Studies with large samples can determine how the symptoms are expressed among children and adolescents of both sexes in different cultures. 
Important notes are due in relation to the findings. Children showed greater feelings of loneliness and helplessness, which could be explained by the fact that they have less social support and greater reliance on family and parents. According to Bowlby (1984), attachment is a primary need, which harnesses the setting of the experience; affective attachment is natural and occurs throughout development, when the child continues to acquire a proper way to handle his/ her relationships and to act in his/her environment. In contrast, adolescents, besides presenting more positive feelings, also had differentiated items, such as low self-esteem and suicide ideation, corroborating the studies by Baji et al. (2009).

Depressive symptoms in different stages of life may actually be distinct and should be analyzed separately, in case of confirmation in other studies, since differences related to sex were only noticeable when the items were analyzed within each age group. The analyzed sample showed that boys marked a larger number of descriptors and consequently showed more negative symptoms (Factor 2) when compared to females, in the anterior and posterior stages of puberty.

Some researchers (Thapar et al., 2012) argue that there are no gender differences in the expression of depressive symptoms prior to puberty. For others (Essau et al., 2010), this difference is more marked, occurring at around 15 to 18 years old. In the current study, however, the differences have been identified since childhood.

These gender differences possibly appeared in early childhood due to the fact that children today have greater skills and greater openness in their social network, which will certainly stimulate talking about feelings, having greater facility to express what they feel. Luby et al. (2003) affirms that, historically, it was believed that children were not able to directly express symptoms and would demonstrate "masked depression". They believe, however, that there is evidence to refute this hypothesis, indicating that the typical symptoms of depression are the most common form and serve as the best clinical markers, even in younger samples. The present study corroborates this assertion, evidencing that the most relevant or nuclear symptoms are linked to sadness, anhedonia and aggressiveness.

Other factors, such as intellectual and hormonal changes, are potential causes of depression (Girgus \& Yang, 2015; Young \& Korszun, 2010). These changes can also cause restlessness, doubts and changes in behavior towards family and/or social groups (Baptista, 2011). Some authors argue that such concerns are possibly related to the loss of protection that parents or others provide in childhood, or even to the adolescents' need to establish their own goals and the need for greater autonomy (Li, Albert, \& Dwelle, 2014). This stage of life is also marked by great emotional intensity, leading to a conflicting relationship with the physical separation of parents and a possible exit from home (Girgus \& Yang, 2015).

About girls, Sloan and Kornstein (2003) also point to crying and greater affective lability as principal symptoms. Carter, Joyce, Mulder, Luty and McKenzie (2000) also found higher scores for changes in appetite (weight gain), sleep disorders and somatization. The girls, then, would have greater comorbidity with internalizing psychological disorders, such as anxiety and eating disorders (Frackiewicz, Sramek, \& Cutler,
2000), which did not occur with the sample of this research.

Some theories propose explanations of gender differences in the expression of depression (Hamilton et al., 2014). For the biological theory, hormones like progesterone, oestrogen and cortisol play an important role in the differences between the sexes in puberty. For Parker and Brotchie (2010), however, there is limited evidence that these hormones significantly influence depressive development in women. Similarly, Frank and Young (2000) suggest that oxytocin increases in women during early puberty, also causing an increase in affiliative behavior and need for emotional approach. The study by Stroud, Papandonatos, Williamson and Dahl (2004) suggested that small differences in the effect of cortisol and regulation of the pituitary gland could lead to an increase in the depression rate among girls during puberty. Possibly, the hormonal changes combined with sociocultural factors could increase the risk of depression (Sloan \& Kornstein, 2003).

Beck's cognitive theory suggests that women have greater interpersonal dependency, necessitating more support from others. Men have more personal independence, are more self-critical and focus more on the expectations of achievement (Stange et al., 2013). Such differences may be explained in the present sample because the analysis of the results reveals that boys have more difficulty socializing.

As noted by Nolen-Hoeksema (2002), women more oriented towards interpersonal relationships tend to have more negative affect and rumination and feel more hopeless. Thus, some results are against and others in favor of those found in current research. For example, both children and male adolescents showed symptoms of loneliness and hopelessness. Sociability seems to be already present in girls and female adolescents. As pointed out by Fanti and Henrich (2010) and Keegstra et al. (2010), the boys present major symptoms of aggression and agitation, and those results were also found in the current research, both in children and adolescents.

Contrary to what Sorensen et al. (2005) appointed, no differences were found in anhedonia and hypersomnia, decreased appetite and concentration among children and adolescents. Some of these features were only noticed when the subdivision with the variable sex was made. In this sense, female children reported better appetites and male teenagers revealed a higher drop in concentration, although one should take into consideration that the comparison sample of the current study is clinical.

Baji et al. (2009) also assessed a clinical sample. In the same way as previous studies, some data refute and others corroborate the current study. Thus, only the difference between children and adolescents is not sufficient for comparison, but the insertion of the sex variable ultimately generates more specific data. Baji et al. (2009) found depressed mood and irritability in children and little more expressive anhedonia. No anhedonia symptom differentiated children and adolescents, even when separated by sex. The depressed mood was more common in adolescent women. Accordingly, it was observed that suicidal ideation is more common in adolescents when compared to children. Another interesting fact is that only a handful of somatic symptoms differentiated the male and female groups with regard to age, 
as the comparative study also pointed out. Finally, in line with the study by Diamantopoulou et al. (2011), Johnson and Whisman (2013) and Rohde et al. (2014), children and adolescent males had higher DIF in depressive symptoms when compared to women.

These results could contribute to the prevention and early detection of mental health disorders, provide support for the elaboration of public policies that aim at prevention or improvements in mental health of children and adolescents and increase the comprehension of symptom differences throughout human development. Some limitations of this research are related to the methodological design (survey), the absence of variability regarding the school type and the use of a single test.

In general, some results corroborated the literature while others did not, evidencing that the test should adopt different standards depending on age and gender. One unaddressed aspect relates to the systematics of the DIF with respect to some group, indicating whether or not this would be uniform. Furthermore, it was not assessed whether the differences reported here would impact - and, if so, to what degree - the extent of youth depression. Studies involving clinical samples should be conducted to ascertain whether differences remain or not.

Future studies may focus on the limitations previously mentioned, especially in investigating the impact of differences. In addition, joint analysis with other instruments assessing the same construct can amplify the understanding of the expression of the disorder in Brazilian children and adolescents.

\section{References}

American Psychiatric Association. (2013). Diagnostic and statistical manual of mental disorders (5th ed.). Washington, DC: Author.

Andersen, E. B. (1973). A goodness of it test for the Rasch model. Psychometrika, 38(1), 123-140. doi:10.1007/ BF02291180

Andrich, D. (1978). A rating formulation for ordered response categories. Psychometrika, 43(4), 561-573. doi:10.1007/ BF02293814

Baji, I., Lopez-Duran, N. L., Kovacs, M., George, C. J., Mayer, L., Kapornai, K., ... Vetro, A. (2009). Age and sex analyses somatic complaints and the symptom presentation of childhood depression in a Hungarian clinical sample. Journal of Clinical Psychiatry, 70(10), 1467-1472.

Baptista, M. N. (2011). Escala Baptista de Depressão - Versão Infanto-Juvenil [Baptista Depression Scale - Toddlers and Teens version] (EBADEP-IJ). Itatiba, SP: Universidade São Francisco.

Benarous, X., Hassler, C., Falissard, B., Consoli, A., \& Cohen, D. (2015). Do girls with depressive symptoms exhibit more physical aggression than boys? A cross sectional study in a national adolescent sample. Child and Adolescent Psychiatry and Mental Health, 9, 41. doi:10.1186/s13034-015-0064-5
Bowlby, J. (1984). Separação: Angústia e raiva [Detachment: Anguish and Angry] (L. Hegenberg, Vol. 2). São Paulo, SP: Martins Fontes.

Carle,A. C., Millsap, R. E., \& Cole, D. A. (2008). Measurement bias across gender on the Children's Depression Inventory: Evidences for invariance from two latent variable models. Educational and Psychological Measurement, 68(2), 281303. doi:10.1177/0013164407308471

Carter, J. D., Joyce, P. R., Mulder, R. T., Luty, S. E., \& McKenzie, J. (2000). Gender differences in the presentation of depressed outpatients: A comparison of descriptive variables. Journal of Affective Disorders, 61(1-2), 59-67. doi:10.1016/S0165-0327(00)00151-8

Chrisman, A., Egger, H., Compton, S. N., Curry, J., \& Goldston, D. B. (2006). Assessment of childhood depression. Child and Adolescent Mental Health, 11(2), 111-116. doi:10.1111/j.1475-3588.2006.00395.x

Diamantopoulou, S., Verhulst, F. C., \& van der Ende, J. (2011). Gender differences in the development and adult outcome of co-occurring depression and delinquency in adolescence. Journal of Abnormal Psychology, 120(3), 644-655. doi:10.1037/a0023669

Eapen, V., \& Crncec, R. (2012). Strategies and challenges in the management of adolescent depression. Current Opinion in Psychiatry, 25(1), 7-13. doi:10.1097/ YCO.0b013e32834de3bd

Essau, C. A., Lewinsohn, P. M., Seeley, J. R., \& Sasagawa, S. (2010). Gender differences in the developmental course of depression. Journal of Affective Disorders, 127(1-3), 185190. doi:10.1016/j.jad.2010.05.016

Fanti, K. A., \& Henrich, C. C. (2010). Trajectories of pure and co-occurring internalizing and externalizing problems from age 2 to age 12: Findings from the National Institute of Child Health and Human Development Study of Early Child Care. Developmental Psychology, 46(5), 1159-1175. doi:10.1037/a0020659

Frackiewicz, E. J., Sramek, J. J., \& Cutler, N. R. (2000). Gender differences in depression and antidepressant pharmacokinetics and adverse events. Annals of Pharmacotherapy, 34(1), 80-88. doi:10.1345/aph.18465

Frank, E., \& Young, E. (2000). Pubertal changes and adolescent challenges: Why do rates of depression rise precipitously for girls between the ages 10 to 15 years? In E. Frank (Ed.), Gender and its effects on psychopathology (pp. 85102). Arlington, VA: American Psychiatric Publishing.

Gaffrey, M. S., Belden, A. C., \& Luby, J. L. (2011). The 2-week duration criterion and severity and course of early childhood depression: Implications for nosology. Journal of Affective Disorders, 133(3), 537-545. doi:10.1016/j. jad.2011.04.056

Girgus, J. S., \& Yang, K. (2015). Gender and depression. Current Opinion in Psychology, 4, 53-60. doi:10.1016/j. copsyc.2015.01.019 
Hamilton, J. L., Hamlat, E. J., Stange, J. P., Abramson, L. Y, \& Alloy, L. B. (2014). Pubertal timing and vulnerabilities to depression in early adolescence: Differential pathways to depressive symptoms by sex. Journal of Adolescence, 37(2), 165-174. doi:10.1016/j.adolescence.2013.11.010

Harkness, K. L., Alavi, N., Monroe, S. M., Slavich, G. M., Gotlib, I. H., \& Bagby, R. M. (2013). Gender differences in life events prior to onset of major depressive disorder: The moderating effect of age. Journal of Abnormal Psychology, 119(4), 791-803. doi:10.1037/a0020629

Johnson, D. P., \& Whisman, M. A. (2013). Gender differences in rumination: A meta-analysis. Personality and Individual Differences, 55(4), 367-374. doi:10.1016/j.paid.2013.03.019

Keegstra, A. L., Post, W. J., \& Goorhuis-Brouwer, S. M. (2010). Behavioural problems in young children with language problems. International Journal of Pediatric Otorhinolaryngology, 74(6), 637-641. doi:10.1016/j.ijporl.2010.03.009

Lei No. 8.069, de 13 de julho de 1990 [Law No. 8.069, de 13 de julho de 1990]. (1990, 16 de julho). Dispõe sobre o Estatuto da Criança e do Adolescente e dá outras providências [On the Status of Children and Adolescents and other measures]. Diário Oficial da União, seção 1. Retrieved from http://www.planalto.gov.br/ccivil_03/ LEIS/L8069.html

Li, S. T., Albert, A. B., \& Dwelle, D. G. (2014). Parental and peer support as predictors of depression and self-esteem among college students. Journal of College Student Development, 55(2), 120-138. doi:10.1353/csd.2014.0015

Lima, D. (2004). Depressão e doença bipolar na infância e adolescência [Bipolar disorder and depression in childhood and adolescence]. Jornal de Pediatria, $80(2$ Suppl.), 11-20. doi:10.1590/S0021-75572004000300003

Luby, J. L. (2010). Preschool depression: The importance of identification of depression early in development. Current Directions in Psychological Science, 19(2), 9195. doi:10.1177/0963721410364493

Luby, J. L., Gaffrey, M. S., Tillman, R., Abril, L. M., \& Belden, A. C. (2014). Trajectories of preschool disorders to full DSM depression at school age and early adolescence: Continuity of preschool depression. The American Journal of Psychiatric, 171(7), 768-776. doi:10.1176/ appi.ajp.2014.13091198

Luby, J. L., Heffelfinger, A., Mrakotsky, C., Brown, K., Hessler, M., \& Spitznagel, E. (2003). Alterations in stress cortisol reactivity in depressed preschoolers relative to psychiatric and no-disorder comparison groups. Archives of General Psychiatry, 60(12), 1248-1255. doi:10.1001/ archpsyc.60.12.1248

Mair, P., \& Hatzinger, R. (2007). Extended Rasch modeling: The eRm package for the application of IRT models in R. Journal of Statistical Software, 20(9), 1-20. Retrieved from https://www.jstatsoft.org/article/view/v020i09/v20i09.pdf
Nolen-Hoeksema, S. (2002). Gender differences in depression. In I. H. Gotlib \& C. L. Hammen (Eds.), Handbook of depression (pp. 492-509). New York, NY: Guilford.

Parker, G., \& Brotchie, H. (2010). Gender differences in depression. International Review of Psychiatry, 22(5), 429-436. doi:10.3109/09540261.2010.492391

Petersen, A. C., Sarigiani, P. A., \& Kennedy, R. E. (1991). Adolescent depression: Why more girls? Journal of Youth and Adolescence, 20(2), 247-271. doi:10.1007/ BF01537611

Rohde, P., Lewinsohn, P. M., Klein, D. N., Seeley, J. R., \& Gau, M. (2014). Key characteristics of major depressive disorder occurring in childhood, adolescence, emerging adulthood, adulthood. Clinical Psychological Science, 1(1), 41-53. doi:10.1177/2167702612457599

Samejima, F. (1969). Estimation of latent ability using a response pattern of graded scores. Psychometrika Monograph Supplement, 34(4, Pt. 2), 100.

Sloan, D. M. E., \& Kornstein, S. G. (2003). Gender differences in depression and response to antidepressant treatment. Psychiatric Clinics of North America, 26(3), 581-594. doi:10.1016/S0193-953X(03)00044-3

Sorensen, M. J., Nissen, J. B., Mors, O., \& Thomsen, P. H. (2005). Age and gender differences in depressive symptomatology and comorbidity: An incident sample of psychiatrically admitted children. Journal of Affective Disorders, 84(1), 85-91. doi:10.1016/j.jad.2004.09.003

Stange, J. P., Boccia, A. S., Shapero, B. G., Molz, A. R., Flynn, M., Matt, L. M., ... Alloy, L. B. (2013). Emotion regulation characteristics and cognitive vulnerabilities interact to predict depressive symptoms in individuals at risk for bipolar disorder: A prospective behavioral highrisk study. Cognition \& Emotion, 27(1), 63-84. doi:10.108 0/02699931.2012.689758

Stroud, L. R., Papandonatos, G. D., Williamson, D. E., \& Dahl, R. E. (2004). Sex differences in the effects of pubertal development on responses to a corticotropin-releasing hormone challenge: The Pittsburgh psychobiologic studies. Annals of the New York Academy of Sciences, 1021, 348-351. doi:10.1196/annals.1308.043

Teresi, J. A., \& Fleishman, J. A. (2007). Differential item functioning and health assessment. Quality of Life Research, 16(Suppl. 1), 33-42. doi:10.1007/s11136-007-9184-6

Thapar, A., Collishaw, S., Pine, D. S., \& Thapar, A. K. (2012). Depression in adolescence. The Lancet, 379(9820), 10561057. doi:10.1016/S0140-6736(11)60871-4

Tsai, J.L., \& Chentsova-Dutton, Y.(2002). Understanding depression across cultures. In I. Gotlib \& C. L. Hammen (Eds.), Handbook of depression (pp. 467-491). New York, NY: Guilford.

Young, E., \& Korszun, A. (2010). Sex, trauma, stress hormones and depression. Molecular Psychiatry, 15(1), 23-28. doi:10.1038/mp.2009.94 
Baptista, M. N., Borges, L., \& Serpa, A. L. O. (2017). Depressive Symptoms: Differences between Gender and Age.

Makilim Nunes Baptista is a Professor at Universidade São Francisco.

Lisandra Borges is a Professor at Universidade São Francisco.

Alexandre Luiz de Oliveira Serpa is Research and Development Manager at Editora Hogreffe Cetepp

Received: Aug. 05, 2015

1st Revision: Dec. 12, 2015

Approved: Apr. 12, 2016

How to cite this article:

Baptista, M. N., Borges, L., \& Serpa, A. L. O. (2017). Gender and age-related differences in depressive symptoms among Brazilian children and adolescents. Paidéia (Ribeirão Preto), 27(68), 290-297. doi: 10.1590/198243272768201706 